\title{
Integrating Online Learning into Workplace Information Systems - Supporting the Goal of Lifelong Learning
}

\author{
${ }^{1,2}$ Lachlan MacKinnon, $\mathrm{PhD},{ }^{1}$ Liz Bacon, $\mathrm{PhD},{ }^{2}$ Olaf Hallan Graven, $\mathrm{PhD}$ and ${ }^{2} \mathrm{Jan}$ Velvin, $\mathrm{PhD}$ \\ ${ }^{1}$ University of Greenwich, UK and ${ }^{2}$ University College of South-East Norway, l.mackinnon@gre.ac.uk, \\ e.bacon@gre.ac.uk,Olaf.Hallan.Graven@hbv.no,Jan.Velvin@hbv.no
}

Abstract: The authors have a significant history of research in online learning, and in recent years have published their work at the LACCEI conference. This paper focuses on the issues caused by the major skills gaps in STEM industries identified in the popular press, and confirmed through empirical research, and the changes to the workforce occasioned by the growing tide of automation. Both of these issues have a similar result on the STEM workforce, in the need to upskill and reskill staff to be productive in the changed landscape brought about by these issues and the accelerating pace of change through technological development. Fundamentally, they argue that there is a need to change the existing model of workplace learning to integrate learning as an integral component of the workplace, rather than an activity that takes place separate from that workplace, often in a separate location. From their own previous research they have encountered both worker and employer resistance to such integration, but they argue the need for cultural and technological change, to enable greater efficiency and availability of appropriate learning resources directly related to workplace activities. By integrating learning environments and resources with the primary information systems in the workplace, and enabling "drill-down" capability to link specific working issues with relevant learning resources, staff efficiency can be improved, better solutions can be developed, and acquisition of skills and knowledge can be improved. The authors provide an example of a working solution, in the tourism domain, from the Tourism Monitor project, which provides both an exemplar and some practical lessons that are relevant to the STEM industries. The Tourism Monitor dashboard provides statistical information collected by the Norwegian government on a number of key tourism datasets, providing information to support the management of tourism services and service organisations. By linking it to an instance of the Sakai VLE, and through that to learning materials developed by the project partners and the local University College, staff development can run alongside the creation and management of tourism services. The authors suggest that a similar model could be used for workplace learning in STEM industries, referencing their own work on developing online learning for collaborative heavyweight processes, such as dCCD, as reported at LACCEI last year. The model developed is novel and built from a considerable body of prior research, and provides an answer to the research question "How could the model of workforce education be changed to ensure the supply of IT and engineering skills in the workforce keeps up with demand?"

Keywords-Online learning, workplace learning, lifelong learning, integrated working and learning environments

\section{INTRODUCTION}

This paper discusses the need to change our approach to engineering education in the context of growing skills shortages in the workforce and the increasing automation of jobs. The traditional approach to engineering education, held by employers and employees, is that education is something that takes place outside of the work environment. However, in the context of future societal change, this is no longer a sustainable approach. The research question discussed here is "How could the model of workforce education be changed to ensure the supply of IT and engineering skills in the workforce keeps up with demand?"

In order to answer this question, this paper first of all discusses the predicted impact of job automation, technology development and challenges, skills shortages and the supply of talent to the industry. This is followed by a section on trends and developments in online and workplace learning. It then discusses the need for an integrated approach to link workplace learning with "normal" workplace activities, and provides an example from the tourism domain that could provide some guidance for use with engineering and IT sectors. It then concludes with a summary of the issues and a consideration of the changes needed to enable this model to taken up within the STEM industries.

\section{WORKFORCE SKILLS SUPPLY AND DEMAND}

This section sets out the background evidence for the need to change the nature of engineering and IT skills education, discussing the challenges around the supply and demand for engineering and IT skills and the predicted impact of job automation, which will result in the need for lifelong reskilling and upskilling, for some people, on a scale not seen to-date.

\section{A. Job Automation}

A study by Oxford University [1] which identifies the jobs most at risk from automation of the workforce in the US puts $47 \%$ of workers at risk in the foreseeable future. Given the many similar articles on this topic, this is clearly a global issue, not just a US issue. Whilst predictions regarding the scale of job automation differ, the story regarding impact is consistent and many have expressed the concern that job automation may widen the gap between the skilled and the 
unskilled as unskilled work tends to be most prone to job automation, although it should be noted that the skilled workforce is not immune [2] with job roles such as materials engineer and scientist being included in the at risk category. Going forward we likely to see are more articles similar to that by Apple in 2016 [3] which discussed the replacement of 60,000 worker in China by robots. The good news is that history tells us technology and automation tends to create more jobs than they destroy [4] (as illustrated in Fig 1 based on evidence from the UK Office of National Statistics), or they at least remain in a steady state [5]. However, going forward, how fast new jobs are created as a result of automation remains unclear [6] [7].

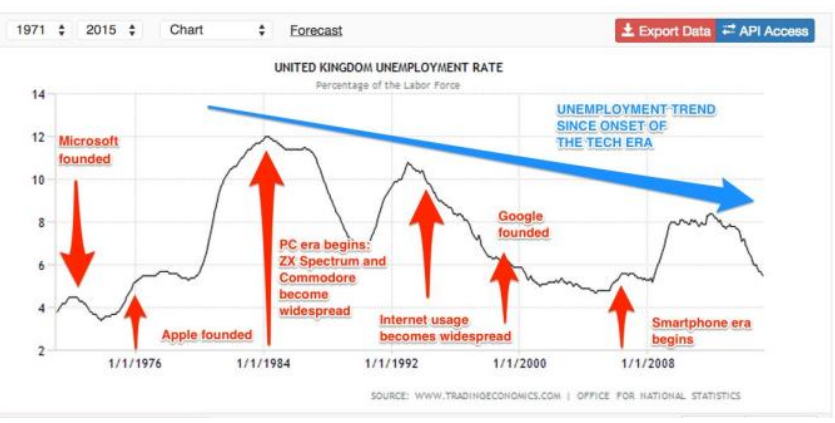

Fig 1. UK Employment rate 1976-2008

The one message that is clear, is that given most automation will be in the lower skills jobs, if employees are not regularly being reskilled or upskilled, the divide between the employed / unemployed, and hence the rich and the poor, is likely to widen. This issue needs to be a high priority for employers to ensure their workforce are appropriately skilled and regularly developed given the increasing propensity of employees to change jobs more frequently, which is only likely to get worse in the context of automation [8].

\section{B. Engineering and IT Workforce Supply and Demand}

There are many reports on the skills shortages of engineers and IT workers. For example in Europe, there are predictions of over 750,000 vacancies by 2020 in the ICT sector alone, the problem being particularly severe in Italy, Germany and the UK [9]. In addition, Europe is predicted to need between 200,000 and 250,000 e-Leaders (simply put these are leaders who can utilise technology to innovate a business) between 2015 and 2020 [10]. Hidden beneath these figures is inequity across countries, with some suffering from higher shortages than others and also considerable gender imbalances. An exellent overview of the forthcoming workforce crisis is given in a book by Dychtwald et al. [11] which discusses a number of factors such as the drop in birthrates leading to a shortage of workers in the workforce, global competition for talent, the impact of increasing longevity, the disproportionate size of the babyboomers population who are now heading rapidly towards retirement and the fact that most organisations still encourage employers out the door when they are close to the traditional retirement age, which could be a big mistake given the lack of young talent coming through, coupled with the potential impact of fluctuating immingration policies, further restricting the supply of talent. In terms of specific disciplines, computer engineers are mentioned as a significant recruitment challenge and these areas are particularly acute in the UK and Europe. For example a report by the Royal Academy of Engineeing in 2015 predicts the need for a million more UK Engineers by 2020 [12] noting that in the UK, women account for less than $10 \%$ of the engineering workforce.

Typically more developed countries e.g. USA and Europe have a worse gender balance in their engineering and IT workforces than many developing countries [13], as is typified by a Scientific American article in 2013 [14] which discusses the different perceptions and attititudes of both men and women, to women studying engineering in higher education. The percentage of women in the engineering and IT workforces has been a major problem for years despite many major initiatives to try and persuade women otherwise. It should be noted that the definition of the IT workforce does vary slightly in the various analyses provided, however, there is no question that there has been a massive decline in women in the IT workforce in some countries, for example in the USA $65 \%$ of computer programmers in 1960 were women [15]. Many reasons have been cited for the drop in interest such as a lack of confidence / anxiety around computers, nerdy image, seen as male-dominated, self-imposed ideas about how men and women should function in a specific society, gender biased environments, understanding of careers, advice from parents, friends, careers advisors etc. who may have little understanding of STEM (science, technology, engineering and maths) careers themselves [16] [17] [18] [19]. Of course there are many sectors of the workforce which do not have a gender balance, so the question is often asked about why it is so important in engineering and IT. Apart from the obvious skills shortage gap, these two areas have such a significant and growing impact in society, many consider it vital that women are fully engaged in these domains in order to fully understand the world around them. Research by McKinsey \& Company has also shown then gender diverse companies are more likely to perform up to $15 \%$ better and ethnically diverse companies, up to $35 \%$ better [20]. The logic of having companies with a workforce that reflects society makes sense however, it is also important to have diversity at all levels. Further research by McKinsey \& company in 2015 on women in the US concluded that "Based on employee pipeline data from 118 companies in 2015 and 60 companies in 2012, two broad themes emerge: women are still underrepresented, and they face real barriers to advancement", it also goes on to say "In fact, at the rate of progress of the past three years, it will take more than 100 years for the upper reaches of US corporations to achieve gender parity" [21]. There are a wide variety of reasons for this which include unconscious bias, workforce 
culture and use of language in job adverts which can put women off applying for jobs and promotion etc. [22] [23].

Research shows that there are good proportions of BAME (Black, Asian and Minority Ethnics) higher education students, (or students of colour) in many traditionally white countries, however, there is considerable evidence that shows people of colour face significant barriers to employment and advancement [24] [25].

\section{TRENDS AND DEVELOPMENTS IN ONLINE LEARNING AND WORKPLACE LEARNING}

The pace of change in the IT and engineering disciplines, and the consequential impact on society means that the existing higher education (HE) model must change in order to fully support the regular upskilling and reskilling of the workforce. Many different approaches have been taken to onthe-job training, short course provision, self-tuition and apprenticeships that have proven extremely successful. A vital area going forward will be the increased use of online education both as support for face-to-face students in a classroom, as well as support for learning in the workplace.

Education is currently going through a technology revolution and it is important to consider how these changes can support the constant upskilling and reskilling needs of the engineering and IT professions. Change will in fact become vital for educational institutions to remain competitive, enhance their reputation and increase student performance and satisfaction. Until now traditional education, as primarily a face-to-face experience in the classroom has been considered the norm, the most efficient, and a good way to introduce students to a topic which they can then practice in laboratories or tutorials. Many academics become anxious if their students do not attend these classes. However considerable research, such as that undertaken by MIT who measured skin conductance of students for a week [26] questions this thinking. Skin conductance can be used as an indication of psychological or physiological arousal, and as can be seen from figure 2, which shows the profile of a typical student for a day, their arousal in class was less then when they were asleep.

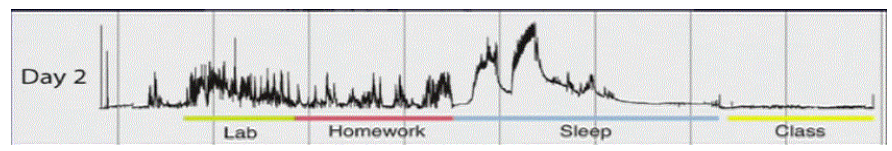

Fig 2. Skin conductance - example student profile

This, coupled with considerable other evidence, suggests that a traditional lecture approach to education may not be the best way to educate students going forward. That doesn't mean they don't have a place in education, however, as discussed by Naik [27], technology has the power to "unleash the academic, empower the student, enhance the learner journey and extend access to those who would previously be denied it".
It is clear that technology has to play a significant part in transforming education in the workplace given we need to grow the workforce much faster than can be achieved by simply increasing higher education student numbers. However, this may require different models for certifying skills and knowledge, to ensure currency and maintain / enhance professionalisation of the industry, given the range of engineering qualifications, and the fact that some disciplines require a license to practice and others, e.g. software engineering, typically do not. This is especially important as we move towards the so-called "unbundling" of higher education [28] [29] which talks about the move to deliver micro and nano courses and degrees, offering a few academic credits that could accumulate over time and evenutally be used towards a qualification. This type of credit accumulation could be extremely useful in the context of the need to constantly upskill and reskill existing workforces. An example of how this might work is demonstrated in figure 3 which shows an example of unbundling in the hotel industry, with a large number of specialist startups taking on functions that are "bundled" as part of the hotel offering.

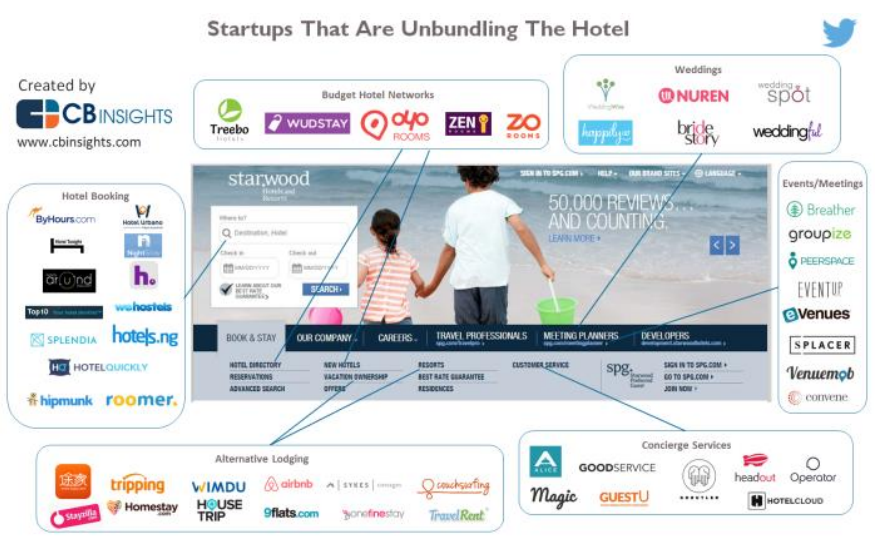

Fig 3 - "Unbundling" in the Hotel Industry

Maintaining and enhancing the professional status of engineering and IT professions cannot be over emphasised. Particularly in the IT industry where numerous and large project failures are frequent, and with such a low barrier to entry e.g. through short how to code courses, the status and standards of the profession clearly need to be raised. The impact of a low barrier to entry is evident from a survey in 2015 by the Washington Post which reported that $69 \%$ of programmers were either self-taught or partially self-taught. They also reported that there was a decrease in computer science degrees awarded and an increase in boot camps which offer short coding courses [30]. The concern being that short rapid introductions to coding are likely to result in poorer quality code and hence damage the image of the profession further through continued project failures and hard to maintain code.

If countries are able to fully utilise the potential of their engineering and IT workforces then we need to ensure the 
highest possible level of skills and knowledge within employees working in organisations responsible for developing advanced systems and inventing new technologies. This approach could also include the use of skills frameworks to identify gaps in workforce individuals. In the area of IT, two common ones used are the European e-Competence Framework [31] and Skills Framework for the Information Age [32], however the identification of skills gaps, relevant credits, the mode of study and funding for education and training, all need a coherent national strategy, in order to support quality lifelong, and timely, learning.

\section{MODELS TO SUPPORT LIFELONG AND WORKPLACE LEARNING IN ENGINEERING EDUCATION}

From the evidence presented in the previous two sections it is clear there is a need to develop new models of education to meet the significant demand and plug the current and future skills shortages predicted in STEM subject areas. This is particularly true for those working in the higher professional levels, where the development of innovative products, and the invention and deployment of new technologies, continue at an ever-increasing pace. However, there are a number of important issues that must be addressed if we are to really develop effective models for lifelong learning, to support the increasing learning needs for those working in STEM careers.

At the start of the century, the authors were involved in several research projects considering the issues of workplacebased learning for staff. For example, the EuroCompetence EU project [33], which although undertaken in the late 90s when technology and the internet were not as sophisticated or developed as they are now, involved seven European universities in five countries, researching open and distance learning aimed at supporting adult learners in the workplace to upskill and reskill. A mechanism was developed to identify skills and knowledge gaps, followed by the implementation of a flexible model for advanced training and education for adult learners, utilising a range of micro credits offered from different universities in the project. This was followed by second European project called MENU (Model for a European Networked University for e-learning) in 2002-3 which developed the idea further to provide a range of online learning credits which could be taken by workforce employees, to fill gaps in their knowledge and skills, from a virtual networked European university, hosted by the partners involved in the project [34].

Another important example of workforce learning was a project called ASTEP which involved the high-tech industries [35] and focused on developing learning support at all levels for staff working in 24/7 production environments, such as semiconductor fabrication. Working direct with staff in such environments produced some interesting results:

$>$ Staff at all levels were in agreement with the concepts of lifelong learning, and the need to continue to develop their skills to reflect the rapidly changing nature of their work.

$>$ Staff on the production floor wanted readilyavailable, easy-to-use briefing and training information, which could also be used as reminders whenever required.

$>$ Staff on the production floor had access to computer systems, but did not wish to undertake training on the floor, apart from practical process-based instruction, and preferred learning to take place in a separate classroom.

$>$ Engineering staff, operating at all levels in the organisation, generally worked at high-end computer workstations, but were unwilling to undertake any form of training using these.

$>$ Managers within the organisation were supportive of staff training, and of the concepts of lifelong learning, but not supportive of training taking place at the same time and using the same equipment as "normal" working.

In fact, one of the key findings of our research projects was that there was both an individual and organisational resistance to the integration of education into standard workplace functions. At all levels within the organisational hierarchy there was an expressed preference for education to take place in a separate situation, be it classroom, with an external training provider, formal education location, or simply a separate room where online training materials could be accessed.

In investigating and discussing these issues with staff and management, concerns were expressed that education was not "working" and therefore would be seen as "stealing time" from projects or assignments. Similarly, it was argued that time spent on education, even if required explicitly for a project or assignment, could not be internally or externally recharged and therefore had to be undertaken separate to the charged work. These viewpoints were commonplace within STEM industries at that time, and a large number of organisations operated learning support and development as a separate activity from "normal" workplace activities. A good example of this is the engineering firm Siemens [36], which has a longstanding and excellent reputation for the quality of its internal learning and certification systems. Siemens have maintained a strong level of separation between their learning and workplace activities, with learning activities being run by a separate organisation within the overall company, which markets those courses and certifications both internally and externally, and they have resisted attempts to map their certifications onto external frameworks.

Whilst organisations like Siemens have continued to offer in-house training to develop their workforce, there has been a significant decline in the number of organisations that do so, with a far greater reliance now on the use of external training organisations, and the recruitment or "poaching" of already trained staff from other organisations [37]. This has resulted in 
a growth in the use of online training resources, both organisationally and individually, but predominantly still seen as separate from workplace activities. Unfortunately, the shortages of skilled STEM personnel described earlier are making the "poaching" strategy much less viable, and organisations are experiencing growing volumes of unfilled vacancies, with many projects failing for lack of skilled staff [38].

Allied to the shortages of skilled STEM personnel, there are the issues associated with the growing size, range and complexity of technologies in use within STEM organisations, and the issues of automation, described earlier. These combine to make the skillsets and roles of existing STEM employees rapidly redundant, and create a requirement for the regular upskilling and reskilling of staff to maintain currency and organisational competitiveness. Organisations such as Agfa [39] have completely transformed their business models and focus, driven by changes in technologies, through a combination of staff redundancies, targeted hiring, and staff retraining. This model of workforce development is not seen as a radical event to happen very occasionally, as would once have been the case, but rather as an annual cycle involving the majority of the workforce. In the face of such continuous change and development, it is no longer viable to see education and training as separate elements from workplace activities, particularly if staff are to utilise new and advanced technologies effectively in their work. The recent growth in the use of MOOCs [40] offers considerable potential for the online provision of education and training, but as the authors described in their LACCEI paper last year [41] there is both a need to provide effective training in the use of such courses to develop metacognitive skills in the learners, and to develop a broad range of such courses to meet different learning requirements. The provision of remote and virtual "lab" facilities online [42] also offers STEM personnel the opportunities to experiment with new and existing technologies relative to workplace activities and project requirements.

Given this scenario, it is neither reasonable nor appropriate for organisations to expect their staff to undertake their own development, in their own time, to keep up to date and reskill themselves. Whilst in many cases this will undoubtedly happen, the Agfa model [39] shows it is important for organisational management to utilise training to shape the workforce to meet workplace needs. Likewise, it is no longer efficient to remove staff from the workplace for training to take place, both because of the loss of time and productivity occasioned by doing so, and because of the ongoing and continuous training needs occasioned by the pace and volume of change in the technologies being utilised in STEM projects. In order to support individual staff development and managerial workforce shaping there is therefore a need to offer an integrated system that incorporates both the tools required to undertake workplace activities and the learning environment to enable staff to acquire and develop the necessary skills and knowledge to undertake those activities. As envisaged in the DECADE project [43] capturing information on individual staff expertise within an integrated system of this type would then enable the creation and dynamic maintenance of an individual profile for each staff member. This could be mapped to a skills / competence framework, such as SFIA [32] or e-CF [31], a qualifications framework, such as EQF [44], and could form the basis for an online authenticated CV. This would be beneficial for organisational managers in recruiting staff, developing project teams, and in identifying and addressing training needs. It would also be beneficial to individuals in enabling them to recognise skills and knowledge gaps, and seek training or support to address them. This model provides both a means to address the issues identified above on workplace training, and a clear path to support lifelong learning.

\section{KEY ISSUES IN INTEGRATING LEARNING TOOLS INTO WORKPLACE SYSTEMS - THE TOURISM MONITOR EXAMPLE}

In considering the integration of learning capabilities with workplace tools, it is important to recognise that, for the majority of professional staff working in the STEM industries, their standard working environment will be computer-based, and they will use management or process information systems to monitor their workplace activities. Whilst there may be other issues for staff working on manufacturing shop floors or similar environments, it is not likely that there will be no engagement with an information system. Accordingly, since these systems also draw data from any specialised software tools in use in the workplace, as well as monitoring general data flows, it would be both logical and relatively straightforward to link any learning capabilities through the primary information system. At a simplistic level, this would provide access to educational and training materials for all staff through a link on the system. However, better integration with the tools in use in the workplace should support a "drilldown" capability, so staff can immediately find relevant learning materials to their current task.

As an example of an integrated system incorporating both a Management Information System and a Virtual Learning Environment, we can consider the system developed by the authors for the Tourism Monitor project [45].

\section{A. The Tourist Monitor System}

The Tourism Monitor project was funded by the Norwegian Research Council and the Buskerud and Nordland regional councils. The work in developing the system and the associated training materials was carried out by the authors, and based in the University College of SouthEast Norway (HSN).

As a core component of the Tourist Monitor project, the project leadership sought to develop a dashboard application, offering flexible and dynamic information comparison and a balanced scorecard model to provide businesses with the 
information and knowledge on existing tourism statistics and trends, covering business, guest and destination indicators, to inform their planning [46]. Dashboards are a particularly popular form of data visualisation application, being seen more and more as a business development tool helping business managers plan and monitor performance quickly and easily [47]. Dashboards have quickly gained currency in a number of application areas, where the need for speed of information is often coupled with the desire to simplify the presentation of the data, or indeed a limited knowledge of the underlying data on the part of the users. This is particularly true in domains such as tourism, where those involved in running the wide range of businesses involved in the tourist industry may have limited knowledge and understanding of the underpinning statistical data models that characterise their industry, but are nonetheless keen to use the information generated from those models to plan and run their business operations. In particular the balanced scorecard model of dashboard information system has been particularly popular in this domain [48], [49].

As is common in the majority of such applications the focus was to provide an intensely graphical application, with limited text and reasonably intuitive and/or familiar interface components to enable users to quickly get to grips with navigation and information generation within the tool. The underpinning datasets used to populate the dashboard are generated from Norwegian government tourism statistics (SSB), collated centrally and circulated quarterly to regional centres, and as indicated above, they focus on three types of indicator - business, guest and destination. These are uploaded into a transactional database, which supports a production rules engine that can generate interface widgets displaying mathematical, logical and/or combinatorial relationships between attributes in the statistical data, e.g. simple statistical comparisons between visitors from different countries in terms of length of stay and type of accommodation. Whilst the transactional database provides access to the current or most recent dataset, a historical data warehouse also sits at the back of the system and can be interrogated to determine trend data over time, e.g. the change over a number of years in the number of visitors from certain countries and the type of accommodation they seek. Clearly such information can be used both to plan the services currently on offer to tourists and also to strategically develop new businesses and services reflecting the trend data determined from the historical data.

With the underlying data structures, and upload and capture facilities, in place, the system then has to provide an appropriate interface to display the outputs of queries and rulebased constructs generated from that data. Fundamentally, the system offers two types of interface, map-based and widgetbased. Map-based interfaces provide relative geographical data, at the level of granularity chosen by the user, against the three types of indicator. Users can drill down or up using simple mouse clicks on the maps, or they can navigate using menu systems if they prefer, particularly useful if they are unfamiliar with the map layout. Figure 4 shows the map layout for the whole country of Norway. Key features of the interface are that it is:

- Fully user-configurable, so the layout, colours and data represented can be fully determined by the users

- Designed responsively, so the interface can be viewed on any device and will configure dynamically to achieve the best representation on that device

- Offered as a web service, so requires no specialist software and can be viewed on any web browser

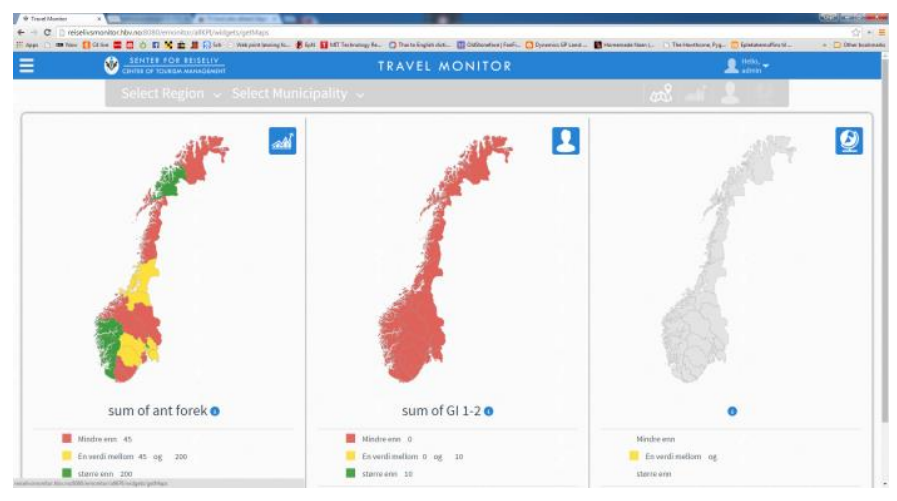

Fig 4: Dashboard Start Page - Business map + guest indicator map + destination map

In contrast to the map-based interfaces, widget-based interfaces are generated through the production rules engine, and therefore represent specific data relationships that the user, or system administrator, wishes to investigate or use to categorise a particular relationship or business element. Widgets are also subject to responsive design, to ensure that they can be viewed and sized appropriately to different devices, although layouts may vary between devices to achieve optimal configurations. To avoid unnecessary clutter on the screen, the administrator can set a threshold limit for the number of widgets that can be supported, and by default this is 9 , reflecting the " $7+/-2$ " rule from HCI research [50] to avoid information overload. Figure 5 shows a widget-based description of the city of Kongsberg in Buskerud, or at least those elements of data about the city that the user thought to be relevant to display.

In both styles of interface, data can be thresholded for comparative purposes between different areas within the region or on a time series basis in individual areas and/or domains, to support balanced scorecard representation. This permits services or businesses to quickly highlight areas of change, where action may be required. 


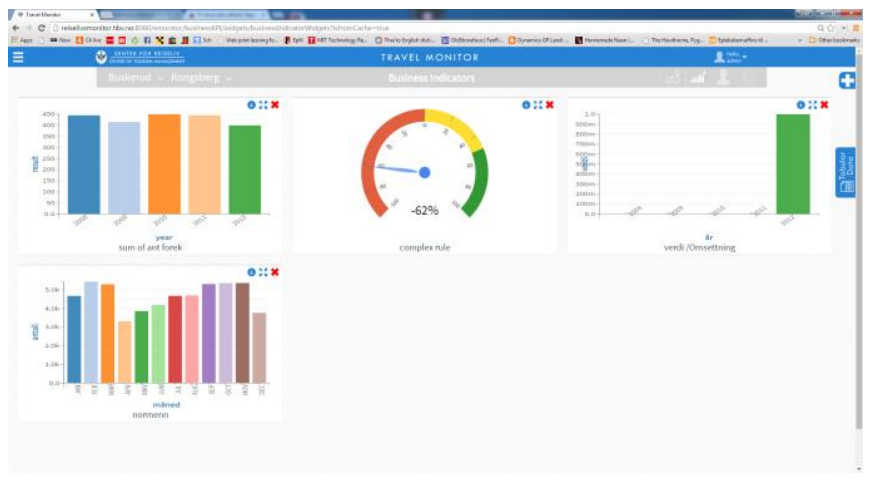

Fig 5: Widget-based view of city of Kongsberg, based on Business Indicator rules

\section{B. Integrating with the Sakai VLE}

As a normal component of the development of the system, the Tourist Monitor application is fully documented, and that documentation is provided within the system as online help facilities to support users and administrators in their use of the system. The documentation model is informed by the minimal manual model proposed by Carroll [51]. The online help is obviously context specific in that the user selection of help relative to a particular component of the system will result in help information relative to that component, however the goal of the system is to provide far more specific context related help. In fact, the dashboard links to an instance of the Sakai virtual learning environment [52], offering context sensitive help relative to the role and domain of the user, which then links to online learning materials developed and provided by the project partners and HSN, in turn linking to academic credit-bearing learning outcomes that could lead to qualifications by credit accumulation. This would allow tourism and public service staff at all levels to become more knowledgeable about the use of statistical information and trend analysis to support their business plans and activities, and then develop further to gain greater knowledge about their domain and tourism and eventually achieve formal qualifications, addressing the need identified by Betts \& Edgell [53]

To support this, users are identified through the normal user-id and password authentication mechanism, and a user profile, developed on user registration, and then extended through usage, is invoked. This enables the system to provide context sensitive help as required, relative to that user's role and domain of work, as well as to the component of the system they are using. From there the user will be able to access online learning materials, specifically relevant to their learning requirements, and their individual learning record. The system will be extended to offer a direct learning interface, and access to individual learning records, in the next version. Obviously, this development is of particular interest to HSN, since it offers a route to provide lifelong learning support to a large sector of the industry and links in to the formal qualification system they provide. Work in this area has already been undertaken in agriculture in New Zealand [54] and in tourism in Sweden [55], but the approach taken in this project is novel, focusing on the development of the dashboard as a virtual learning environment.

\section{Relevance to STEM industries}

Whilst the domain of operation described in the previous sections is tourism, and therefore clearly not STEM, the issues described and addressed are common. There is a need to provide workplace based learning opportunities to upskill and reskill staff, particularly in working with what, for them, are new and complex technologies. In terms of time commitments and loss of productivity there is a need to provide the learning opportunities in the workplace, but to link to external sources and particularly to certification and qualification frameworks. In their LACCEI paper last year [41] the authors discussed the difficulties of learning heavyweight collaborative processes, particularly Distributed CCD [56], in a MOOC context. However, using an integrated workplace-based learning model would enable most of those difficulties to be overcome, and thereby offer an added value to the online learning provision. Since heavyweight collaborative processes are a significant feature of much work in the STEM industries, this is another strong argument for the development and deployment of an integrated workplace learning model.

\section{DISCUSSION, CONCLUSIONS AND FUTURE WORK ON WORKPLACE LEARNING IN ENGINEERING}

Given the growth of technology and the predictions around job automation, there is a growing need to be able to rapidly reskill and upskill the workforce, particularly STEM professionals, both now and in the future. Tertiary education, as a sector, needs to consider how education can genuinely support lifelong learning and to develop more effective and efficient models to support workplace learning. Given the skills shortages identified earlier this demand is becoming increasingly pressing as the strategy employed in some sectors, such as the capability to poach staff, diminishes in the face of the increasing demand.

Based on previous projects by the authors, there has been significant resistance by both workforce and management within the STEM industries to the concept of fully integrated workplace learning. Both groups expressing a preference for separate working and learning environments. However, given the societal shift in the use of technology in the past 10+ years, and the pace of change and learning that will be required as we go forward, workplace learning will be required to ensure greater efficiency and better outcomes. Not only is classroom based learning inefficient for many reasons, for example due to the time people have to take away from work resulting a loss of workplace time and productivity, but unless the learning is used immediately much of it is forgotten. 
Integrating learning with workplace activity can provide immediacy of learning at the point it is needed, and therefore promotes retention of the knowledge and skills gained more effectively. In order to support integrated workplace learning we need to develop linked software systems, which pull together management information systems, dashboards, and learning environments. These should offer the drill-down capability to follow a problem experienced in the workplace, through to some appropriate learning materials, which can link to further external learning materials if needed, as described earlier.

In order for this new approach to be successfully implemented, the following changes need to take place within STEM workplaces:

1. Staff and management have to accept the need to undertake learning within the workplace situation, which is a cultural change.

2. Technology needs to be developed to ensure effective integration between existing workplace tools, learning environments and external sources, which is a technology change.

3. Systems need to be developed to capture individual staff expertise, to support managerial selection of staff against projects, and to enable staff to develop their own skills, which is both a technological and cultural change.

4. Work needs to be undertaken to consider the mapping between identified skills within the workforce and skills frameworks e.g. SFIA [32] and qualifications frameworks such as EQF [44] in order to support worker mobility and organisation selection and skills planning.

5. This work could be used to realise the aim of the DECADE project [43] to develop an authenticated CV for individuals that could be the basis of a future professional certification and licensing for those areas of STEM that do not currently offer this.

This work has sought to address the research question, "How could the model of workforce education be changed to ensure the supply of IT and engineering skills in the workforce keeps up with demand?", and the authors believe that the model we have described in this paper enables us to answer that question affirmatively. The model described in the Tourism Monitor project is novel, and builds on many years of research in this area, leveraging the benefits of the developments in technology to overcome the drawbacks.

Most importantly, the authors believe that this approach can meet the long-term goal of lifelong learning and ensure that we will achieve the best results in terms of skilling our professional STEM staff. It will also improve efficiency and will therefore help to address the speed and diversity of change with which we are currently faced, and which will, from the evidence provided earlier, require increasingly intense and more frequent learning.

\section{ACKNOWLEDGMENT}

We wish to acknowledge the Norwegian Research Council, the Regional Council of Buskerud, the Regional Council of Nordland, and the University College of SouthEast Norway, for funding and hosting the Tourism Monitor project.

\section{REFERENCES}

[1] Frey, Carl Benedikt and Osborne, Michael A. The future of employment: How susceptible are jobs to computerisation?, Oxford Martin, 2013.

[2] Marketwatch 2015. "80 Million US Jobs at Risk from Automation, Central Bank Official Says." http://www.marketwatch.com/story/eightymillion-us-jobs-at-risk-from-automation-central-bank-official-says-201511-12, 2015.

[3] Apple 2016. "Apple replaces 60K people with robots" http://futurism.com/apple-supplier-just-cut-60000-jobs-replaces-factoryworkers-with-robots/, 2016

[4] Business Insider UK 2015. "This idea that technology destroys jobs is garbage", 2015.

[5] Deloitte 2015. "Technology and people: The great job-creating Machine" http://www2.deloitte.com/content/dam/Deloitte/uk/Documents/finance/de loitte-uk-technology-and-people.pdf, 2015.

[6] Brynjolfsson, E. \& McAfee, A., 2012. "Race Against the Machine: How the Digital Revolution is Accelerating Innovation, Driving Productivity, and Irreversibly Transforming Employment and the Economy." MIT Press, ISBN 9780984725113, 2012.

[7] MIT 2013. "How technology is destroying jobs". https://www.technologyreview.com/s/515926/how-technology-isdestroying-jobs/, 2013.

[8] Harris, Peter. 2015. How many jobs should you expect to hold in your lifetime? Workopolis. http://careers.workopolis.com/advice/how-manyjobs-should-you-expect-to-hold-in-your-lifetime/, 2015.

[9] e-skills Manifesto 2015. http://eskills4jobs.ec.europa.eu/c/document_library/get_file?uuid=b69ba1 d7-6db4-415d-82e4-ac4d700a38b8\&groupId=2293353, 2015.

[10] EU 2015 "e-Leadership Skills for Small and Medium Sized Enterprises". http://eskills-lead.eu/fileadmin/lead/reports/lead_final_report.pdf, 2015.

[11] Dychtwald, K., Erickson, T.J. and Morison, R., 2006. Workforce crisis: How to beat the coming shortage of skills and talent. Harvard Business Press., 2013.

[12] Independent 2015. UK needs over one million new engineers and technicians, says Royal Academy of Engineering. http://www.independent.co.uk/news/uk/home-news/uk-needs-over-onemillion-new-engineers-and-technicians-says-royal-academy-ofengineering-10334994, 2015.

[13] Galpin, V. (2002). Women in computing around the world. ACM SIGCSE Bulletin, 34(2), 94-100., 2002.

[14] Aggarwal, Varun 2013. Engineering Is a Man's Field: Changing a Stereotype with a Lesson from India. https://blogs.scientificamerican.com/guest-blog/engineering-is-amane28099s-field-changing-a-stereotype-with-a-lesson-from-india/, 2013. Galpin, V. (2002). Women in computing around the world. ACM SIGCSE Bulletin, 34(2), 94-100., 2002.

[15] Gürer, D. (2002). Pioneering women in computer science. ACM SIGCSE Bulletin, 34(2), 175-180., 2002.

[16] Unger, R. K. (1979). Toward a redefinition of sex and gender. American Psychologist, 34(11), 1085., 1979.

[17] Huffman, A. H., Whetten, J., \& Huffman, W. H. (2013). Using technology in higher education: The influence of gender roles on technology self-efficacy.Computers in Human Behavior, 29(4), 17791786., 2013.

[18] Lovegrove, G., \& Segal, B. (Eds.). (2013). Women into computing: selected papers 1988-1990. Springer Science \& Business Media., 2013.

[19] Wyer, M., Barbercheck, M., Cookmeyer, D., Ozturk, H., \& Wayne, M. (2013).Women, science, and technology: A reader in feminist science studies. Routledge., 2013. 
[20] McKinsey \& Company, by Vivian Hunt, Dennis Layton, and Sara Prince. 2015 "Why diversity matters" http://www.mckinsey.com/business-functions/organization/ourinsights/why-diversity-matters, 2015.

[21] McKinsey \& Company 2015 Women in the Workplace. http://www.mckinsey.com/business-functions/organization/ourinsights/women-in-the-workplace, 2015.

[22] Guardian, How unconscious bias holds us back. http://www.theguardian.com/women-inleadership/2014/may/01/unconscious-bias-women-holding-back-work 1st may 2014., 2014.

[23] Gaucher, D., Friesen, J. and Kay A.C. Evidence That Gendered Wording in Job Advertisements Exists and Sustains Gender Inequality. Journal of Personality and Social Psychology. 2011, Vol. 101, No. 1, 109 -128. http://gender-decoder.katmatfield.com/static/G, 2011.

[24] Shapiro, T., Meschede, T., and Osoro, S. The Roots of the Widening Racial Wealth Gap: Explaining the Black-White Economic Divide. Insitute of Assets and Social Policy, Research and Policy Brief Feb 2013. http://www.naacpldf.org/files/case_issue/Shapiro\%20, 2013.

[25]Royal Academy of Engineering. Engineering graduates highly employable - but ethnicity still a barrier, says Academy. Nov 2016 http://www.raeng.org.uk/news/newsreleases/2016/november/engineering-graduates-highly-employable-butethnic, 2016.

[26] Zoh, M-Z., Swenson, N.C. and Picard, R. W. A Wearable Sensor for Unobtrusive, Long-Term Assessment of Electrodermal Activity. IEEE TRANSACTIONS ON BIOMEDICAL ENGINEERING, VOL. 57, NO. 5, MAY 2010. http://affect.media.mit.edu/pdfs/10.Poh-etal-TBME-EDAtest, 2010.

[27] Naik, R. An E-DUCATION. RSA Journal Issue 3, 2015., 2015.

[28] Craig, R. 2015 “College Disrupted: The Great Unbundling of Higher Education.” St. Martins Press. ISBN 978-1137279699, 2015.

[29] University Ventures 2012. "The Great Unbundling - Popping Bundles, Not Bubbles". http://universityventures.com/publications.php?title=thegreat-unbundling, 2012.

[30] Turner, K. Lots of coders are self-taught, according to developer survey. https://www.washingtonpost.com/news/the-switch/wp/2016/03/30/lots-ofcoders-are-self-taught-according-to-developersurvey/?utm_term=.8e22c978b6e2, 2016.

[31] e-CF 2016. European e-Competence Framework. http://www.ecompetences.eu, 2016.

[32] SFIA 2016. The Skills Framework for the Information Age. http://www.sfia-online.org/en, 2016.

[33] Windall Gill, Bacon Liz and Chadwick David. "Open and Distance Learning via the Internet: Who provides it, What do Companies want from it? Some findings of the EuroCompetence project". Published in "Inspire V Quality and Software Development: Teachi, 2000.

[34] Model for a European Networked University for e-learning 2003. http://ans.hsh.no/lu/inf/menu/, 2003.

[35] McAndrew, P., MacKinnon, L. \& Rist, R. 2002. “A Framework for work-based networked learning." Journal of Interactive Learning Research, V.13, N.1, pp.149-165. ISSN - 1093-023X

[36]Siemens Training. https://www.sitrain-learning.siemens.com/UK/ Accessed 15/12/2016

[37] Panagiotakopoulos, A. (2012) "Staff "poaching" in the small business context: overcoming this key barrier to training", Industrial and Commercial Training, Vol. 44 Iss: 6, pp.326 - 333

[38] Rossi, B. (2006) "IT project failure due to lack of skills." Information Age 10/02/2006, http://www.information-age.com/emc-cut-in-half306211 Accessed 15/12/2016.

[39] Agfa Academy Training Platform, reported in Agfa Gevaert Annual Report 2014.

https://solutions.vwdservices.com/products/documents/838ce0b0-dbad48c4-b381481521c847a5/?c=d4ILkSwxrp6rxia8YwIl3AlxngFSk82OEQcjGvQyJm8 2AwLsf6TzvSzRJFSHAcmP Accessed 15/12/2016

[40] Beaven, T., Hauck, M., Comas-Quinn, A., Lewis, T. \& d.1.Arcos, B., (2014), MOOCs: Striking the Right Balance between Facilitation and SelfDetermination, MERLOT Journal of Online Learning and Teaching, V. 10, N. 1, March 2014.
[41] Bacon, L. \& MacKinnon, L. (2016) "The Challenges of Creating Successful Collaborative Working and Learning Activities in Online Engineering Courses." Proceedings of the $14^{\text {th }}$ LACCEI Multi-Conference for Education, Engineering and Technology, 20-22 July 2016, San Jose, Costa Rica.

[42] Samuelsen, D.A.H. \& Graven, O.H. (2016) “ Remote laboratories in engineering education - an overview of implementation and feasibility." Proceedings of the $14^{\text {th }}$ LACCEI Multi-Conference for Education, Engineering and Technology, 20-22 July 2016, San Jose, Costa Rica.

[43] Bacon E, MacKinnon L. "Automated Student Portfolio Development and Verification for Expertise Capture in Learning and Development Activities - the DECADE Approach". In proceedings of Global Learn Asia Pacific 2010 Conference on Learning and Technology Penang, Malaysia, May 17-20, 2010.

[44]European Qualifications Framework. 2012. http://www.accreditedqualifications.org.uk/european-qualificationsframework-eqf.html Accessed 15/12/2016.

[45] MacKinnon, L., Velvin, J., Graven, O.H. \& Bacon, L. (2015) "Using a Dashboard-based Statistical Information System to Support Online Learning - The Tourism Monitor Project.” E-Learn: World Conference on E-Learning in Corporate, Government, Healthcare and Higher Education 2015, pp. 1126-1135

[46]Malhotra, Y. (2005). Integrating knowledge management technologies in organizational business processes: getting real time enterprises to deliver real business performance. Journal of knowledge management, 9(1),pp. 728.

[47]Eckerson, W. (2011), Performance Dashboards - Measuring, Monitoring and Managing your Business 2nd edition, John Wiley, ISBN 978-0-47058983-0

[48]Kaplan, R. S., \& Norton, D. P. (1996). The balanced scorecard: translating strategy into action: Harvard Business Press

[49]McPhail, R., Herington, C., \& Guilding, C. (2008). Human resource managers' perceptions of the applications and merit of the balanced scorecard in hotels. International Journal of Hospitality Management, 27(4), pp.623-631. doi: http://dx.doi.org/10.1016/j.ijhm.2007.06.004

[50]Miller, G.A. (1956) "The magical number seven, plus or minus two: Some limits on our capacity for processing information." Psychological Review, V.63, N.2, pp. 81-97. doi: 10.1037/h0043158

[51]Carroll, J.M. (1990), The Nurnberg Funnel: designing minimalist instruction for practical computer skill, MIT Press

[52] Sakai Learning Environment. https://sakaiproject.org Accessed $15 / 12 / 2016$

[53]Betts, K. \& Edgell, D.L. (2013), “Online Education and Workforce Development: Ten Strategies to Meet Current and Emerging Workforce Needs in Global Travel and Tourism", Journal of Tourism and Hospitality, 2:1, 1000108, pp. 1-9. doi:10.4172/2167-0269.1000108

[54]Moller, H., Barber, A., Saunders, C., MacLeod, C., Rosin, C., Lucock, D., Manhire, J. (2012). The New Zealand sustainability dashboard: unified monitoring and learning for sustainable agriculture in New Zealand (ARGOS Working Paper No. 8). Agriculture Research Group on Sustainability. Retrieved from http://hdl.handle.net/10523/5284

[55]Fuchs, M., Hopken, W. \& Lexhagen, M. (2015), “Applying Business Intelligence for Knowledge Generation in Tourism Destinations - A Case Study from Sweden", Tourism and Leisure 2015, pp. 161-174, Springer, ISBN 978-3-658-06659-8

[56] Stamatis, D., Hansson, B., Hjeltnes, T.A. \& MacKinnon, L. (2015). A Distributed Concurrent Design based e-Learning approach to Entrepreneurship Education. Proceedings of ICEIRD 2015 (8th International Conference for Entrepreneurship, Innovation and Regional Development), 18-19 June 2015, Sheffield, UK. 